\title{
Fatty acid composition in amorphous aggregates in the northern Adriatic Sea
}

\author{
Mirjana Najdek* \\ Ruđer Bošković Institute, Center for Marine Research Rovinj, 52210 Rovinj, Croatia
}

\begin{abstract}
The fatty acid compositions of amorphous aggregates were determined in samples collected in northern Adriatic regions of different eutrophication degree and in different seasonal conditions of the plankton communities. It was shown that healthy and active phytoplankton can be present in the aggregate communities, particularly various diatom species. Four different groups of aggregates were sorted by cluster analysis, comparing fatty acid proportions and ratios $(\mathrm{C} 16: 1 / \mathrm{C} 16: 0, \mathrm{C} 16: 1 / \mathrm{C} 18: 1$ and C16POLY/C18POLY). The growth stages of the aggregate diatom populations included the lag, exponential and stationary growth phases as well as decay phases. The aggregate diatom composition of several samples was significantly different from the surrounding water. The results confirmed a previous hypothesis that the northern Adriatic aggregates represent self sustaining communities developing throughout the summer.
\end{abstract}

KEY WORDS: Aggregates Fatty acids Phytoplankton Diatoms Northern Adratic

\section{INTRODUCTION}

Ecological studies of amorphous aggregations (marine snow) started in 1986 in the northern Adriatic Sea (Herndl \& Peduzzi 1988). They were intensified after 1988, 1989 and 1991 when unusually large quantities of mucilaginous aggregates appeared during summer in the water column of the entire region (Stachowitsch et al. 1990, Degobbis et al. 1995). These studies were mostly related to the abundance and organic production of autotrophic and heterotrophic plankton communities in the aggregates and the different ability of the major zooplankton species to feed upon the mucoid matrix (see Herndl 1992, Malej \& Harris 1993, Malej 1995 for review and references).

The formation of marine snow in the ocean can be due to various mechanisms (Alldredge \& Silver 1988), but in the northern Adriatic it seems to be caused primarily by mucopolysaccharides released by phytoplankton (Posedel \& Faganeli 1991, Fogg 1995). Aggregate accumulation usually occurs after phytoplankton blooms (induced by significant freshwater

•E-mail: najdek@more.cim.irb.hr nutrient inputs), and it is also enhanced by an inefficient zooplankton grazing (Herndl 1992). In years when the phytoplankton exudation is unusually high during spring and summer, the mucoid material may gradually grow, particularly in the pycnocline layer, when the turbulent shear is low. In such cases, clouds and gelatinous layers (Stachowitsch et al. 1990) can develop, in addition to flocs and stringers. Hypertrophic mucilage aggregation can be related to periodical (10 to $50 \mathrm{yr}$ ) unusual climatic and, consequently, environmental (hydrologic, oceanographic) conditions (Crisciani et al. 1991, Degobbis et al. 1995).

The marine snow microenvironment is greatly enriched with inorganic and organic nutrients and planktonic organisms, and the composition of phytoplankton species is often different from the surrounding water (Revelante \& Gilmartin 1991, Kaltenböck \& Herndl 1992). Particularly enriched are some diatom species, as for instance Nitzschia closterium (Degobbis et al. 1995, Monti et al. 1995). Moreover, from primary production measurements it was estimated that the aggregate autotrophic community accounted for up to $70 \%$ of the total water column production in 1987 in diatom dominated marine snow (Herndl 1988), but for at least 
$40 \%$ in 1991 in cyanobacterial dominated aggregates (Kaltenböck \& Herndl 1992).

It was suggested that aggregation is a part of the life histories of many diatom species (Smetacek 1985) and significantly determined by the species composition of the bloom and their differential aggregation capability (Riebesell 1991, Crocker \& Passow 1995). The sticking coefficient of diatoms is species specific and depends on their physiological stage (Kiørboe et al. 1990).

To verify if phytoplankton (primarily diatoms) can actively grow in the amorphous aggregates of the northern Adriatic, its growth stages were estimated from fatty acid analyses. To achieve this aim, criteria were elaborated to distinguish the contribution of different species to the changes in the aggregate fatty acid composition from the changes caused by their growth.

\section{MATERIALS AND METHODS}

Research area. In the western part of the northern Adriatic (Stns 101 and 108; Fig. 1) the influence of the nutrient input (mainly discharged by the Po River of Italy, one of the largest in the Mediterranean area) is very marked. Here intense microplankton blooms,

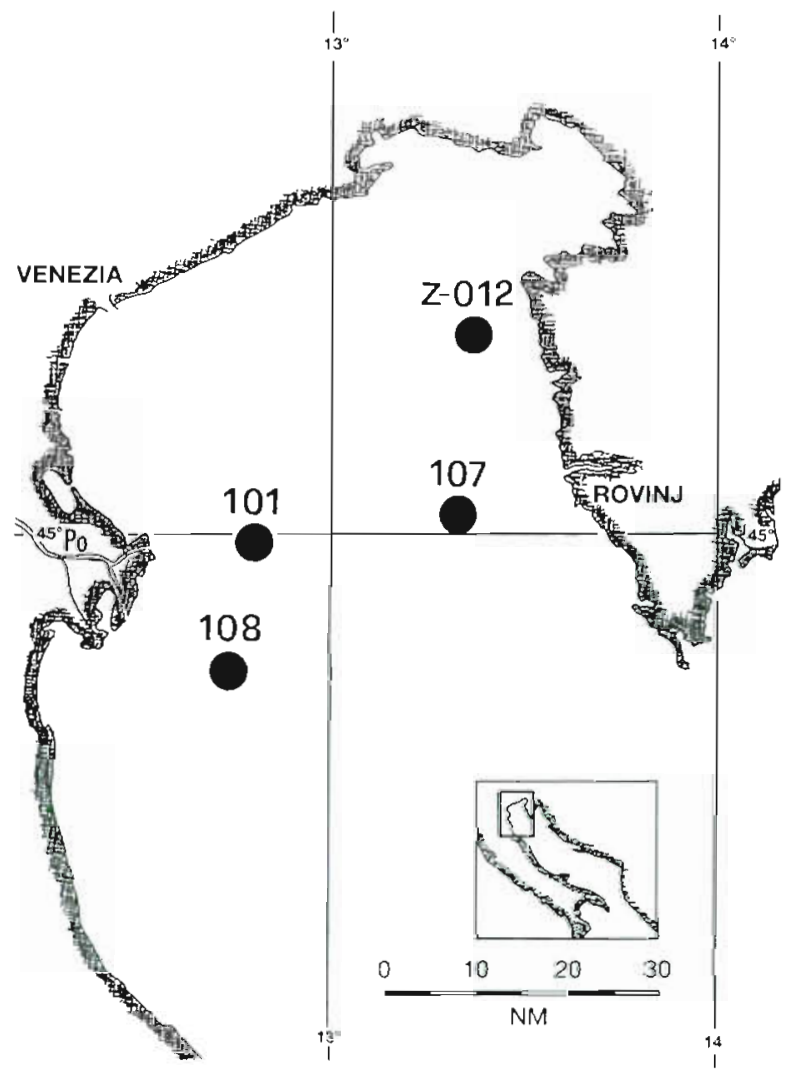

Fig. 1. Sampling locations in the northern Adriatic Sea often monoalgal diatom dominated, can occur (Skeletonema costatum in winter, some Nitzschia and Chaetoceros species in spring and autumn; e.g. Degobbis et al. 1995). In contrast, the eastern side (Stns 107 and Z-012) is much more oligotrophic due to the incoming current from the central Adriatic (Gilmartin et al. 1990). The nanoplankton (nanoflagellate) abundance is generally higher at the western stations and accounts for the largest part of the phytoplankton counts in the entire region, except during the microplankton blooms (Smodlaka 1986). Despite the marked eutrophication gradient, aggregates were observed in the entire investigated area and may in part be redistributed by currents, particularly during summer when eddy currents prevail.

Sampling. Aggregate samples (18) were collected from at least one of the 4 investigated stations (Fig. 1) in July-August 1991, October 1993, February, March, and May-July 1994 (Table 1). The bottom depths of the stations are $25 \mathrm{~m}$ (Stn Z-012), $32 \mathrm{~m}$ (Stns 101 and 108), and $36 \mathrm{~m}$ (Stn 107). Aggregates were collected by SCUBA divers with $20 \mathrm{ml}$ graduated polyethylene syringes with forward ends cut off at depths of the highest aggregate density (usually the pycnocline layer). For sampling convenience, aggregates as similar as possible in shape (macroflocs) and appearance (generally $>5 \mathrm{~mm}$ ) were selected and sucked into the syringe with a minimal amount of surrounding water. The samples for phytoplankton counts in aggregates and seawater were preserved with a neutralized Lugol's solution. Half litre samples for chlorophyll a (chl a) determination (0.5 l) were filtered on $\mathrm{GF} / \mathrm{C}$ Whatman glass microfibre filters (1.2 $\mu \mathrm{m}$ pore size), and stored at $-20^{\circ} \mathrm{C}$ until analysis in the onshore laboratory.

Phytoplankton counts. The micro- and nanophytoplankton fractions (i.e. cells larger and smaller than $20 \mu \mathrm{m}$, respectively) were counted by inverted microscopes using the Utermöhl method. Identified species (diatoms and dinoflagellates) were classified as microplankton. Nanoflagellates could not be counted in the aggregates, because of high quantities of organic detritus.

Chlorophyll a determination. The chl a concentrations were determined fluorometrically (Farrand F-4 fluorometer), after extraction of the filters with $90 \%$ acetone. The analyses were performed in seawater samples only

Fatty acid analysis. The syringe contents with aggregates were transferred onto ignited (2 $\mathrm{h}$ at $\left.380^{\circ} \mathrm{C}\right) 4.7 \mathrm{~cm}$ GF/F Whatman glass microfibre filters, and left for a few minutes under a slight vacuum to remove excess seawater. The procedure for the fatty acids extraction and isolation is described in detail in Najdek et al. (1994). GLC analyses were carried out 
on a gas chromatograph HP 5730A on a capillary column (methyl silicone, $25 \times 0.2 \mathrm{~mm}$ ). Oven temperature was programmed from 70 to $270^{\circ} \mathrm{C}$ at a rate of $4^{\circ} \mathrm{C} \mathrm{min}^{-1}$ Peaks were identified by means of reference standards and by comparison of the relative retention indices. The fatty acids were quantified by an internal standard (heptadecanoic acid, C17:0). Blanks were evaluated applying the described extraction procedure on thermally treated filters before sample filtration.

Data analysis. To verify the grouping in data a multivariate procedure (cluster analysis) was applied. The analysis is based on the correlation coefficients matrix of each variable (fatty acids proportions and ratios) with every other one. The samples (aggregates) are successively fused into groups, starting with samples with the highest mutual correlation coefficients and $F$-ratios $(p<0.01)$, then gradually lowering the similarity level at which groups are fused and ending in a single cluster. The process is represented by a tree diagram or dendrogram (joining method). The most similar groups to those found by the joining procedure were chosen and their ranges and means were calculated ( $\mathrm{K}$ means method). The statistical data analysis was performed on PC by commercial software packages (Systat 5.0).

\section{RESULTS}

The aggregate samples were collected in extremely different conditions of the ecosystem. In summer 1991 well developed mucilaginous aggregates, including large clouds (up to $4 \mathrm{~m}$ in diameter), filled most parts of the water column in the investigated area, and gelatinous layers covered large portions of the sea surface. Moreover, in June of that year a marked dinoflagellate bloom (Prorocentrum minimum) occurred in succession to the usual diatom spring blooms. In October 1993 the Po River freshwater discharge was unusually high and marked diatom blooms occurred over most parts of the northern Adriatic, including the area of Stn 107 (chl a concentration up to $21 \mu \mathrm{g}$ $\mathrm{dm}^{-3}$; Table 1). In contrast, a moderate bloom was observed in spring 1994. In winter and summer 1994 the freshwater influence, and consequently the phytoplankton standing crop, was as low as usual in these seasons. In 1993 and 1994 only flocs and stringers were present.

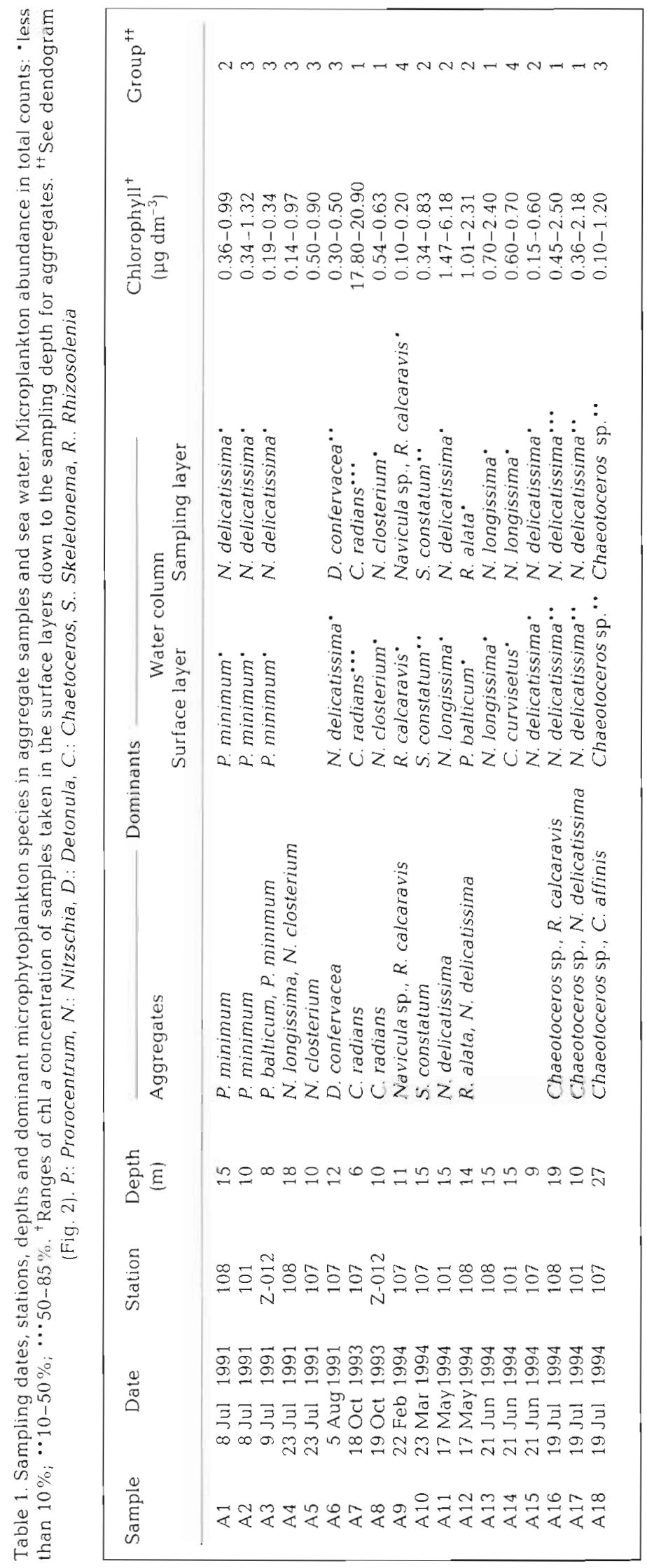


Within the microplankton fraction, diatoms dominated in most of the aggregate samples, except in A1, A2 and A3 (July 1991), in which dinoflagellates were found (Table 1). In 6 (A3, A8, A12, A16, A17, and A18) of the total 13 samples for which complete phytoplankton count data were available, the composition of aggregates and surrounding waters differed substantially. In 2 other cases (A1 and A2) the aggregate dominant species were also determined as dominant in the surface layer, from which they might have originated. Interestingly, in a third of the aggregate samples ( $A 1$, A2, A5, A8, A10, A11), 1 species markedly dominated ( 72 to $99 \%$ of the total microplankton counts), while only in sample A9 (Feb. 1994) were 3 species of approximately equal abundance (Table 2 ). In the remainder of the samples (mostly collected in summer, except A12) a second species significantly contributed to the total counts ( 25 to $49 \%$ ) in addition to the dominant one $(44$ to $61 \%)$.

The fatty acids determined in the aggregates most probably originated from embedded phytoplankton, since their composition was quite similar to that described for natural phytoplankton populations. The saturated fatty acids dominated in all samples, but in very variable percentages (48 to $77 \%$; Table 3 ). Among them $\mathrm{C} 16: 0$ was found in highest concentrations, while C14:0 and C18:0 alternately represented a second major component. The other saturated compounds were insignificant. Within the monounsaturated fraction (18 to $41 \%$ ) the relative importance of particular components, especially palmitoleic $(\mathrm{C} 16: 1 \mathrm{n}-7)$ and oleic (C18:1n-9) acids, changed significantly among aggregates as indicated by the ratio between both. Similar behaviour was also observed within the polyunsaturated fatty acid (PUFA) fraction ( 3 to $20 \%$ ) particularly for 16POLY and 18POLY. Unsaturated versus saturated fatty acid content (UNS/SAT) ratio, generally used as an indicator of the degree of organic matter degradation, also varied considerably.

To investigate whether some samples had a more similar fatty acid composition than others all the obtained data for the diatom dominated aggregates (A4-A18; Table 3) were compared by cluster analysis complete linkage method. Similar samples were sorted into 4 groups, with different fatty acid characteristics (dendrogram; Fig. 2). These differences were particularly evident between Group 1 and the other groups. To simplify a more detailed analysis of the defined groups, only selected components (C14:0, C16:0, C16:1, and C16POLY = C16:2+C16:3+C16:4, C18:1 C18POLY $=$ C18:2+C18:3+C18:4, C20:5, C22:6) were considered. These components accounted for at least 60 to $80 \%$ of the total fatty acid contents, and their ratios (C16:1/C16:0, C16:1/C18:1 and C16POLY' C18POLY) were additionally used to determine the diatom growth stage. Ranges and means of these components and ratios, including UNS/SAT ratios, were calculated for each aggregate group (Table 4).

Group 1 was characterized by the highest mean values and ranges for $\mathrm{C} 14: 0$ and $\mathrm{C} 16: 1$, but by the lowest for C16:0 and C18:1 compared with the other groups (Table 4). Moreover, in these aggregates

Table 2. Distribution of microphytoplankton species (\% of total numbers counted) in the aggregate samples

\begin{tabular}{|c|c|c|c|c|c|c|c|c|c|c|c|c|c|c|c|}
\hline & \multicolumn{15}{|c|}{ Samples } \\
\hline & A 1 & $\mathrm{~A} 2$ & A3 & A4 & A5 & A6 & A7 & A8 & A.9 & A10 & A.11 & A 12 & A 16 & A17 & A 18 \\
\hline \multicolumn{16}{|l|}{ Diatoms } \\
\hline Chaetoceros radians & - & - & - & - & - & - & 60.2 & 74.8 & 2.2 & 0.1 & - & - & - & - & - \\
\hline Chaetoceros sp. & - & - & - & - & - & - & 14.3 & 24.2 & - & - & - & - & 57.5 & 43.6 & 51.5 \\
\hline Chaetoceros affinis & - & - & - & - & - & - & - & 1.1 & - & - & - & - & 8.9 & 12.6 & 36.5 \\
\hline Nitzschia longissima & - & 2.5 & - & 60.6 & 14.4 & 1.9 & 0.8 & 0.1. & 1.4 & - & 66 & - & 0.7 & 0.6 & - \\
\hline Nitzschia closterium & - & - & - & 39.2 & 84.6 & 25.6 & 1.7 & 0.2 & 2.9 & - & - & - & - & - & - \\
\hline Nitzschia delicatissima complex & - & 3.4 & - & - & - & 7.8 & - & 0.1 & - & 0.4 & 71.9 & 27.4 & 3.4 & 32.7 & 6.8 \\
\hline Skeletonema costatum & - & - & - & - & - & - & - & - & - & 99.1 & 1.3 & - & - & - & - \\
\hline Rhizosolenia fragillissima & - & 0.5 & - & - & - & 3.9 & - & 0.1 & - & - & 19.3 & 50.9 & 0.1 & 2.2 & 0.2 \\
\hline Rhizosolenia alata & 8.1 & 6.2 & - & - & - & 0.9 & - & 0.1 & - & 0.1 & 0.1 & 3.9 & 0.1 & - & 0.6 \\
\hline Rhizosolenia calcaravis & - & - & - & - & - & - & - & - & 32.8 & - & - & - & 24.6 & - & 0.1 \\
\hline Detonula confervacea & - & 1.5 & - & - & - & 48.1 & - & - & - & - & - & - & - & 1.2 & - \\
\hline Navicula sp. & - & - & - & - & - & - & - & - & 21.1 & - & - & - & - & - & - \\
\hline Asterionella & - & - & - & - & - & - & 20.6 & - & - & - & - & - & - & - & - \\
\hline Others & - & - & - & - & - & 1.7 & - & - & 39.4 & 0.3 & - & 15.6 & 4.3 & 5.3 & 3.9 \\
\hline \multicolumn{16}{|l|}{ Dinoflagellates } \\
\hline Prorocentrum minimum & 90.2 & 78.4 & 49.1 & - & - & 8.2 & - & - & - & - & 0.4 & - & - & - & - \\
\hline Prorocentrum balticum & - & - & 50.9 & - & - & - & - & - & - & - & - & - & - & - & \\
\hline Prorocentrum micans & - & - & - & 0.1 & 1 & - & - & - & - & - & - & - & - & - & - \\
\hline Others & 1.8 & 4.9 & - & - & - & 1.7 & 0.2 & 0.1 & - & - & 0.4 & 1.9 & 0.5 & 0.2 & 0.6 \\
\hline
\end{tabular}


Table 3. Fatty acid composition in the aggregates ( $\%$ of total fatty acids). UNS/SAT: ratio of unsaturated versus saturated fatty acid content

\begin{tabular}{|c|c|c|c|c|c|c|c|c|c|c|c|c|c|c|c|c|c|c|}
\hline Fatty acid & A.1 & $\mathrm{A} 2$ & A3 & $\mathrm{A} 4$ & A5 & A6 & A.7 & A8 & A9 & A10 & A 11 & A12 & A 13 & A 14 & A15 & A 16 & A.17 & A18 \\
\hline \multicolumn{19}{|c|}{ Saturated (SAT) } \\
\hline 14:0 & 12.96 & 17.81 & 10.25 & 17.25 & 14.04 & 17.48 & 21.77 & 20.88 & 5.68 & 15.87 & 12.90 & 10.36 & 13.34 & 8.42 & 13.08 & 20.32 & 21.22 & 18.87 \\
\hline $15: 0 t$ & 1.64 & 1.76 & 2.29 & 2.42 & 4.88 & 2.16 & 2.28 & 3.63 & 2.33 & 2.46 & 3.13 & 5.06 & 3.29 & 3.46 & 1.23 & 5.89 & 5.05 & 5.03 \\
\hline $16: 0$ & 30.71 & 41.32 & 36.97 & 35.40 & 36.03 & 33.67 & 19.82 & 25.38 & 28.32 & 21.85 & 23.35 & 22.53 & 20.86 & 26.21 & 29.02 & 24.74 & 25.64 & 31.25 \\
\hline $17: 0 t$ & 0.32 & 1.22 & 1.06 & 0.84 & 1.78 & 1.05 & 0.04 & 0.02 & 3.85 & 1.55 & 1.67 & 1.61 & 1.94 & 1.39 & 1.05 & 0.77 & 1.17 & 1.15 \\
\hline 18:0 & 7.15 & 11.43 & 17.85 & 7.28 & 5.68 & 8.20 & 5.68 & 7.03 & 17.32 & 4.91 & 7.58 & 7.68 & 6.12 & 11.58 & 5.32 & 7.72 & 8.24 & 9.36 \\
\hline 19.0 & 0.41 & 0.32 & 0.16 & 0.31 & 0.25 & 0.69 & 0.04 & 0.12 & 0.16 & 1.00 & 1.00 & 1.00 & 1.18 & 1.00 & 1.00 & 0.24 & 0.22 & 0.14 \\
\hline $20: 0$ & 2.95 & 2.02 & 2.25 & 2.14 & 3.26 & 5.21 & 0.46 & 0.31 & 0.33 & 1.04 & 1.06 & 1.10 & 1.23 & 1.37 & 1.14 & 0.30 & 1.36 & 1.26 \\
\hline $22: 0$ & 1.71 & 1.19 & 0.00 & 2.18 & 2.28 & 3.23 & 0.00 & 0.22 & 0.63 & 0.65 & 0.95 & 0.00 & 0.52 & 0.21 & 0.15 & 0.00 & 0.09 & 1.32 \\
\hline \multicolumn{19}{|c|}{ Monounsaturated (MONO) } \\
\hline $16: 1$ & 18.52 & 8.23 & 7.13 & 12.66 & 12.77 & 10.97 & 22.58 & 10.29 & 14.44 & 19.65 & 18.96 & 16.15 & 29.79 & 8.38 & 20.20 & 24.38 & 17.74 & 12.62 \\
\hline $18: 1(n-9)$ & 11.70 & 7.52 & 10.24 & 11.34 & 13.32 & 10.69 & 8.53 & 10.03 & 13.37 & 16.00 & 17.96 & 19.98 & 8.19 & 14.85 & 13.63 & 3.39 & 5.49 & 8.22 \\
\hline $18: 1(n-7)$ & 3.16 & 1.45 & 2.93 & 3.33 & 1.94 & 2.48 & 1.32 & 1.02 & 2.32 & 0.65 & 2.32 & 1.72 & 1.22 & 1.23 & 1.89 & 0.18 & 1.62 & 1.16 \\
\hline $20: 1$ & 1.29 & 0.40 & 0.41 & 0.19 & 0.30 & 0.35 & 0.09 & 0.02 & 1.23 & 1.61 & 1.06 & 1.10 & 0.46 & 1.19 & 1.14 & 0.30 & 1.36 & 0.16 \\
\hline $22: 1$ & 0.15 & 0.22 & 0.13 & 0.19 & 0.21 & 0.14 & 0.05 & 0.05 & 1.25 & 0.18 & 0.83 & 1.52 & 0.21 & 0.66 & 0.27 & 0.11 & 0.12 & 0.13 \\
\hline $16: 1 / 18: 1$ & 1.58 & 1.09 & 0.70 & 1.12 & 0.96 & 1.03 & 2.65 & 2.02 & 1.08 & 1.23 & 1.06 & 0.81 & 3.64 & 0.56 & 1.48 & 7.19 & 3.23 & 1.54 \\
\hline $16: 1 / 16: 0$ & 0.60 & 0.20 & 0.19 & 0.36 & 0.35 & 0.33 & 1.14 & 0.80 & 0.51 & 0.90 & 0.81 & 0.72 & 1.43 & 0.32 & 0.70 & 0.99 & 0.69 & 0.40 \\
\hline \multicolumn{19}{|c|}{ Polyunsaturated (PUFA) } \\
\hline $16: 2$ & 0.28 & 0.12 & 0.00 & 0.81 & 0.32 & 0.23 & 3.64 & 1.83 & 0.28 & 2.43 & 1.21 & 1.24 & 1.29 & 0.23 & 1.12 & 2.29 & 2.53 & 1.12 \\
\hline $16: 4$ & 0.06 & 0.00 & 0.00 & 0.28 & 0.29 & 0.23 & 3.26 & 0.99 & 0.67 & 1.87 & 0.85 & 1.11 & 1.18 & 1.36 & 1.00 & 1.18 & 1.33 & 1.33 \\
\hline $16: 3$ & 0.35 & 0.00 & 0.00 & 0.43 & 0.16 & 0.18 & 2.87 & 1.34 & 0.32 & 1.68 & 0.92 & 0.98 & 0.78 & 1.65 & 1.23 & 2.33 & 1.99 & 0.99 \\
\hline $18: 4$ & 1.15 & 0.43 & 0.44 & 0.21 & 0.13 & 0.19 & 0.32 & 1.34 & 1.55 & 0.25 & 0.56 & 0.55 & 0.37 & 1.66 & 0.35 & 0.32 & 0.06 & 0.16 \\
\hline $18: 3$ & 0.10 & 1.10 & 0.56 & 0.33 & 0.21 & 0.18 & 0.89 & 0.28 & 0.64 & 0.53 & 0.56 & 0.38 & 1.09 & 1.50 & 0.99 & 0.26 & 0.16 & 1.27 \\
\hline $18: 2$ & 1.58 & 1.74 & 2.63 & 0.77 & 0.30 & 0.24 & 1.21 & 1.49 & 1.62 & 0.97 & 1.61 & 2.26 & 1.62 & 3.16 & 1.56 & 0.91 & 0.50 & 1.56 \\
\hline $20: 5$ & 1.34 & 0.32 & 0.80 & 1.30 & 1.24 & 1.27 & 4.38 & 2.60 & 0.73 & 3.62 & 1.12 & 2.62 & 3.13 & 1.73 & 2.66 & 3.38 & 2.11 & 1.68 \\
\hline 22.6 & 2.47 & 1.40 & 3.90 & 0.34 & 0.61 & 0.98 & 0.59 & 1.08 & 2.71 & 1.04 & 0.40 & 1.05 & 2.19 & 8.66 & 1.90 & 0.99 & 2.00 & 1.22 \\
\hline $16 \mathrm{POLY}$ & 0.69 & 0.12 & 0.00 & 1.52 & 0.77 & 0.64 & 0.77 & 4.16 & 1.27 & 5.98 & 2.98 & 3.33 & 3.25 & 3.24 & 3.35 & 5.80 & 5.85 & 3.44 \\
\hline 18POLY & 2.83 & 3.27 & 3.63 & 1.31 & 0.64 & 0.61 & 2.42 & 3.11 & 3.81 & 1.75 & 2.73 & 3.19 & 3.08 & 6.32 & 2.90 & 1.49 & 0.72 & 2.99 \\
\hline $16 \mathrm{P} / 18 \mathrm{P}$ & 0.24 & 0.04 & 0.00 & 1.16 & 1.20 & 1.05 & 4.04 & 1.34 & 0.33 & 3.42 & 1.09 & 1.04 & 1.06 & 0.51 & 1.16 & 3.89 & 8.13 & 1.15 \\
\hline SAT & 57.85 & 77.07 & 70.83 & 67.82 & 68.20 & 71.69 & 50.27 & 57.59 & 58 & 49 & $\jmath$ & & & & & 39. & 62.99 & 68.38 \\
\hline MONO & 34.82 & 17.82 & 20.84 & 27.71 & 28.54 & 24.63 & 32.57 & 31.41 & 32.61 & 38.09 & 41.13 & 40.47 & 39.87 & 26.31 & 37.13 & 28.36 & 26.33 & 22.29 \\
\hline PUFA & 7.33 & 5.11 & 8.33 & 4.47 & 3.26 & 3.50 & 17.16 & 10.95 & 8.52 & 12.39 & 7.23 & 10.19 & 11.65 & 19.95 & 10.81 & 11.66 & 10.68 & 9.33 \\
\hline UNS/SAT & 0.73 & 0.30 & 0.41 & 0.47 & 0.47 & 0.39 & 0.99 & 0.74 & 0.70 & 1.02 & 0.94 & 1.03 & 1.06 & 0.86 & 0.92 & 0.67 & 0.59 & 0.46 \\
\hline
\end{tabular}

C16POLY was particularly abundant while C18POLY was comparatively low. Consequently, the ratios C16:1/C16:0, C16:1/C18:1, and C16POLY/C18POLY were the highest. Although the C20:5 proportions were low in all the analysed aggregates they were the largest in this group. The UNS/SAT ratios were significantly higher than for Groups 3 and 4, but the maximum mean value was obtained for Group 2. In the aggregates of this latter group the proportions of C16:1, C16POLY, and C20:5 were higher than in those from Groups 3 and 4, while the mean value for C18:1 was the highest among all the samples. Thus, the characteristic fatty acid ratios, although lower than in Group 1 aggregates, were higher than for the remaining groups.

The maximal C16:0 mean value was obtained for Group 3 (Table 4). Consequently, the lowest C16:1/ C16:0 ratio was obtained for this group. The C18:1 and C16:1 proportions were lower in Group 3 aggregates than those in Groups 1 and 2. Their ratio was on average close to 1, similar to Group 2 aggregates. Group 3 was also characterized by the lowest C16POLY, C18POLY, and C22:6 contents, with C16:1/C18:1 ratios only slightly higher than 1 The lowest contribution of PUFAs in this group resulted in minimal UNS/SAT ratios relative to the other groups. The fatty acid composition of these aggregates was additionally characterized by relatively high proportions of C18:1(n-7), C15t and C17t fatty acids compared to the other samples (Table 3).

In contrast, in the samples of Group 4, maximal proportions of C18POLY (and consequently minimal C16POLY/C18POLY ratios) and C22:6 were measured (Table 4). However, the $\mathrm{C} 14: 0$ and $\mathrm{C} 16: 1$ proportions were the lowest, with minimal C16:1/C16:0 and C16:1/C18:1 ratio values.

The ranges for the major fatty acid proportions (C14:0, C16:0 and C16:1) and C16:1/C16:0, C16:1/ 


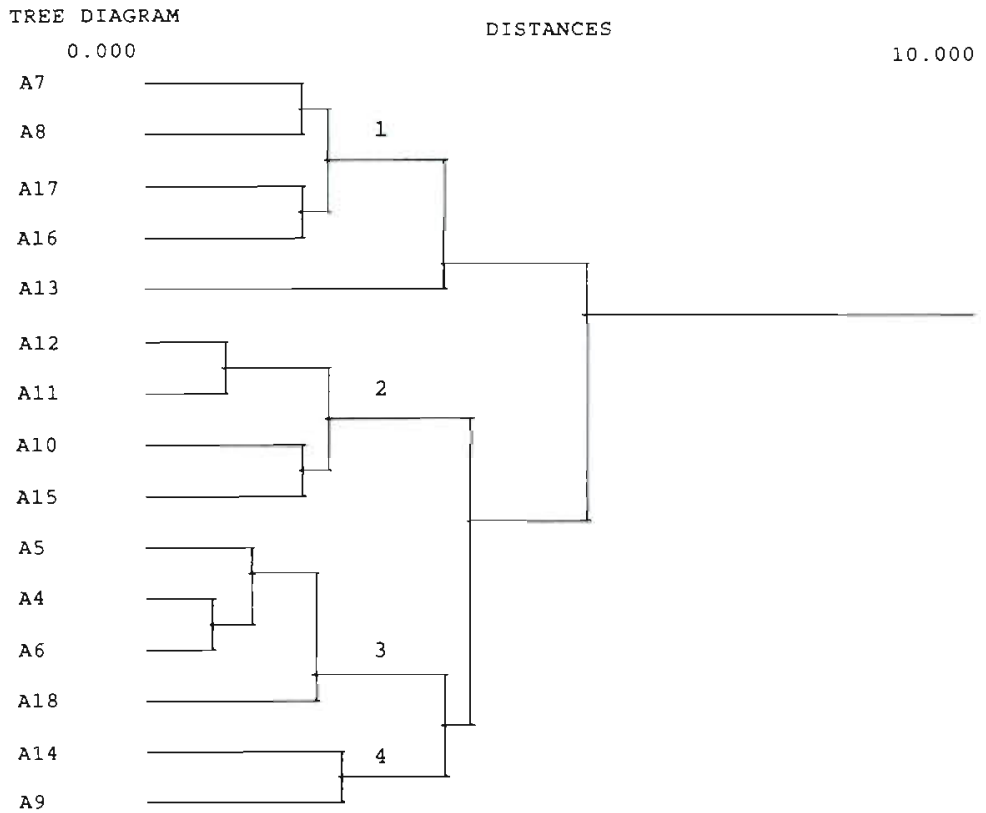

Fig. 2. Cluster analysis dendrogram (complete linkage method - farthest neighbor) of fatty acid composition and their ratios $\mathrm{C} 16: 1 / \mathrm{C} 16: 0$, C16:1/C18:1, C16POLY/C18POLY of aggregate samples

C18:1, and UNS/SAT ratios in the dinoflagellate dominated aggregate sample A1 were similar to those for the diatom dominated aggregate Group 2. However, in contrast to Group 2, the C16POLY/ C18POLY ratio was lower than 1. The compositions of samples A2 and A3 were similar to Group 3, with the difference being that the C16POLY/C18POLY $(0.00$ to 0.04$)$ and UNS/SAT $(0.30$ to 0.41$)$ ratios were much lower than in diatom dominated aggregates.

\section{DISCUSSION}

The fatty acid composition can be used as a chemotaxonomic marker for phytoplankton species, taking into account that it also depends upon their growing conditions and growth phase (Kattner et al. 1983, Morris et al. 1985, Mayzaud et al. 1989, 1990, Volkman et al. 1989, Dunstan et al. 1994). Thus, it is essential to develop a method to separate the contribution of different species from effects due to processes during their growth, which both cause changes in the fatty acid composition of natural samples.

The fatty acids from diatoms have been extensively studied and are readily distinguishable from those of other microalgal classes (Volkman et al. 1989, 1991, Dunstan et al. 1994). Diatoms from healthy cultures, harvested near the end of the logarithmic growth phase, are characterized by high proportions of $\mathrm{C} 16: 1, \mathrm{C} 16: 0, \mathrm{C} 14: 0$, and C20:5 fatty acids. The proportion of C16:1 usually exceeds that of $\mathrm{C} 16: 0$ by a factor of 1 to 3 . Higher values of C16POLY than of C18POLY, with C16POLY/C18POLY ratios much higher than 1, are also typical for diatoms.

In natural diatom populations during blooms developed under natural conditions (Kattner et al. 1983, Mayzaud et al. 1989) or in in situ experimental large bags (Morris et al. 1985, Mayzaud et al. 1990), the fatty acid proportions were similar to those measured in laboratory cultures, but with lower absolute contents. Approximately the same composition was also observed in the investigated aggregates from Group 1.

Table 4. Ranges and means of relevant fatty acid proportions and ratios in 4 groups of aggregate samples (Fig. 2). UNS/SAT: ratio of unsaturated versus saturated fatty acid content

\begin{tabular}{|c|c|c|c|c|c|c|c|c|}
\hline & \multicolumn{2}{|c|}{ Group 1} & \multicolumn{2}{|c|}{ Group 2} & \multicolumn{2}{|c|}{ Group 3} & \multicolumn{2}{|c|}{ Group 4} \\
\hline & Range & Mean & Range & Mean & Range & Mean & Range & Mean \\
\hline $14: 0$ & $1334-21.77$ & 19.51 & $10.36-15.87$ & 13.05 & $14.04-18.87$ & 16.91 & $5.68-8.42$ & 7.05 \\
\hline $16: 0$ & $19.82-25.64$ & 23.29 & $21.85-29.02$ & 24.19 & $31.25-36.03$ & 34.09 & $26.21-28.32$ & 27.26 \\
\hline $16: 1$ & $17.74-29.79$ & 22.96 & $16.15-20.20$ & 18.74 & $10.97-12.77$ & 12.26 & $8.38-14.44$ & 11.41 \\
\hline $18: 1$ & $3.39-10.03$ & 7.13 & $13.63-19.89$ & 16.89 & $8.22-13.32$ & 10.89 & $13.37-14.85$ & 14.55 \\
\hline $16: 1 / 16: 0$ & $0.69-1.43$ & 1.01 & $0.70-0.90$ & 0.78 & $0.33-0.40$ & 0.36 & $0.32-0.50$ & 0.41 \\
\hline $16: 1 / 18: 1$ & $2.02-7.19$ & 3.75 & $0.80-1.48$ & 1.14 & $0.96-1.54$ & 1.16 & $0.56-1.08$ & 0.82 \\
\hline 16POLY & $3.25-9.77$ & 5.77 & $2.98-5.98$ & 3.91 & $0.64-3.44$ & 1.59 & $1.27-3.24$ & 2.25 \\
\hline 18POLY & $0.72-3.11$ & 2.16 & $1.75-3.19$ & 2.64 & $0.61-2.99$ & 1.39 & $3.81-6.32$ & 5.07 \\
\hline $16 \mathrm{P} / 18 \mathrm{P}$ & $1.06-8.13$ & 3.69 & $1.04-3.42$ & 1.68 & $1.05-1.20$ & 1.14 & $0.33-0.51$ & 0.42 \\
\hline$C 20: 5$ & $2.11-4.38$ & 3.12 & $1.12-3.62$ & 2.50 & $1.24-1.68$ & 1.37 & $0.73-1.73$ & 1.23 \\
\hline $\mathrm{C} 22.6$ & $0.59-2.19$ & 1.37 & $0.40-1.90$ & 1.10 & $0.34-1.22$ & 0.79 & $2.71-8.66$ & 5.68 \\
\hline UNS/SAT & $0.59-1.06$ & 0.81 & $0.92-1.03$ & 0.90 & $0.39-0.47$ & 0.45 & $0.70-0.86$ & 0.78 \\
\hline
\end{tabular}


The ranges for major fatty acid proportions, as well as for $\mathrm{C} 20: 5$ and $\mathrm{C} 22: 6$ and ratios C16POLY/C18POLY, C16:1/C18:1 and C16:1/C16:0 (Fig. 2, Table 4), were similar to those reported by the above cited authors. This indicates that a healthy diatom population at the highest growth stage was present in these aggregates. In only 1 (A7) of 4 (A7, A8, A16, A17) samples assigned to Group 1, the microphytoplankton composition was similar to that determined in the water (Table 1 ). This was the case during the unusually marked Chaetoceros radians bloom in October 1993. In contrast, the A16 aggregate population was dominated by Chaetoceros $\mathrm{sp}$. and Rhizosolenia calcaravis, although sampled during a moderate bloom of Nitzschia delicatissima complex, which occurred in the entire water column. The remaining 2 aggregates were sampled when the microplankton biomass in the water column was very low (less than $2 \%$ of the total phytoplankton counts). For this reason, the fatty acid pattern, assessed in these aggregates, should confirm the view (Revelante \& Gilmartin 1991, Riebesell 1991) that diatom cells embedded in a mucous matrix maintained their growth.

The phytoplankton growth characteristics in the other aggregates can be inferred from fatty acid composition changes, which occur in periods between initial (low productivity) and the end (high productivity) of exponential growth phases. Particularly useful for this purpose are the proportions and ratios between C16POLY and C18POLY as well as between C16:1 and C18:1. Their variations in response to the growth stage of diatom population have been described in the numerous studies cited above.

Even though the proportions of the major fatty acid components in the Group 2 aggregates (Fig. 2, Table 4) might indicate the prevalence of a population at the highest growth stage, this was not supported by the C16/C18POLY, C16:1/C18:1 and C16:1/C16:0 ratios which were significantly lower than in Group 1 aggregates. However, a decrease of the C16POLY/18POLY values could partly result from changes in diatom species composition. This might be the case for the A11 and A12 samples, in which Rhizosolenia sp. contributed significantly to the microplankton population. In fact, a much lower C16POLY/C18POLY ratio (1.5) was determined in this species compared to other diatoms (Dunstan et al. 1994). However, larger C18:1 proportions than expected and $\mathrm{C} 16: 1 / \mathrm{C} 18: 1$ ratio values close to 1 argued against the presence of cells at the highest growing stage in the aggregates from Group 2. Actually, the C18:1 proportion never exceeds $6 \%$ and the $\mathrm{C} 16: 1 / \mathrm{C} 18: 1$ ratio is not lower than 4 in diatoms at the end of the exponential growth phase (Volkman et al. 1989, Dunstan et al. 1994). On the contrary, the C16POLY/C18POLY and C16:1/C18:1 ratio ranges obtained for the Group 2 aggregates are in good agreement with those observed during the midexponential growth phase of Chaetoceros calcitrans and Phaeodactyium tricornutum cultures (FernandezReiriz et al. 1989) as well as during the progressive increase of diatom populations in mixed phytoplankton communities (Kattner et al. 1983, Morris et al. 1985. Mayzaud et al. 1989).

A fatty acid composition characteristic for populations in the lag phase was recognized in aggregates A9 and A14 (Group 4), which were sampled during low primary production periods and high species diversity of the phytoplankton community in the surrounding water. This was particularly indicated by the minimal C16:1/C18:1 and C16POLY/C18POLY ratios (significantly lower than 1) and relatively low $\mathrm{C} 16: 1 / \mathrm{C} 16: 0$ value ranges compared with the other groups (Table 4). Moreover, according to Morris et al. (1985) nanoflagellates might also significantly contribute to the increase of the C18POLY and C18:1 proportion levels.

The aggregates of Group 3 (Fig. 2) were also collected in conditions of minimum phytoplankton growth, but the fatty acid composition revealed a significant detrital contribution. In addition to the lower PUFA and higher saturated fatty acid proportions as well as consequent minimal UNS/SAT ratios, higher bacteriological marker proportions $[C 18: 1(n-7)$ and C15 fatty acids] were measured in these aggregates compared to those from the other groups. Similar characteristics, indicating prevailing senescence conditions in the microphytoplankton community after the bloom decay and successive increase of heterotrophic bacterial activity, were also observed in aggregates A2 and A3 dominated by dinoflagellates. These aggregates and the Group 3 samples were taken in summer 1991 in the presence of high quantities of large mucilaginous aggregates. In that period the environmental conditions were obviously unfavourable for microphytoplankton growth, both in water and in aggregates. This is also supported by the fact that an unusually intense cyanobacterial bloom developed at that time (Fuks 1995). Cyanobacteria very probabiy took advantage of conditions succeeding in competition with microphytoplankton.

This study has shown that fatty acid ratios can represent very useful discriminating parameters to evaluate the growing phases of diatom populations. Furthermore, it was shown that not only diatoms in the late exponential or stationary phases, when the stickiness between the cells is enhanced due to extracellular mucopolysaccharide releases (Smetacek 1985), can be associated with the aggregate communities, but also those in the initial or lower growth stages. In fact, the fatty acid composition of several analysed aggregates suggested that 
a healthy phytoplankton community can develop on mucus, often dominated by other species than those in the water column and in different growth stages.

Usually, amorphous aggregates sink relatively fast and, hence, they can represent an important food transfer mechanism to organisms living in deeper layers or on the sea bottom (Alldredge \& Silver 1988). However, in the northern Adriatic during summer, in conditions of high water column stability, the aggregate residence time in the water column can be much. longer than in a less strongly stratified environment. Then aggregates become self sustaining communities with their own primary production and recycling of organic matter, and resist a breakup at least up to the end of summer, when the increased water column dynamics become a major factor controlling aggregate size and distribution.

Acknowledgements. The help of A. Bakota and R. Rabak, CMR divers and the crew of RV 'Vila Velebita' during sampling and analyses is greatly appreciated. The author is grateful to Dr Danilo Degobbis, Prof. Dr Noelia Revelante, and Prof. Dr Malvern Gilmartin for a critical review of the manuscript. Comments by 3 anonymous reviewers substantially improved the final manuscript. The work is financially supported by the Ministry of Science and Technology (Project No. 1-08-229) and the State Directorate for the Environment of the Republic of Croatia (Alpe-Adria Project, Observatory for the Northern Adriatic)

\section{LITERATURE CITED}

Alldredge AL, Silver MA (1988) Characteristics, dynamics and significance of marine snow. Prog Oceanogr 20:41-82

Crisciani F, Ferraro S, Raicich F (1991) Climatological remarks on the algal bloom episodes of 1729 and 1991 in the northern Adriatic Sea. Boll Oceanol Teor Appl 9:367-370

Crocker KM, Passow U (1995) Differential aggregation of diatoms. Mar Ecol Prog Ser 11.7:249-257

Degobbis D, Fonda-Umani S, Franco P, Malej A, Precali R, Smodlaka $N$ (1995) Changes in the northern Adriatic ecosystem and the hypertrophic appearance of gelatinous aggregates. Sci Total Environ 165:43-58

Dunstan GA, Volkman JK, Barrett SM, Leroi JM, Jeffrey SW (1994) Essential polyunsaturated fatty acids from 14 specles of diatom (Bacillariophyceae). Phytochem 35:155-161

Fernandez-Reiriz MJ, Perez-Camacho A, Ferreiro MJ, Blanco J, Planas M. Campos MJ, Labarta U (1989) Biomass production and variation in the biochemical profile (total protein, carbohydrates, RNA, lipids and fatty acids) of seven species of marine microalgae. Aquaculture 83:17-37

Fogg GE (1995) Some speculations on the nature of the pelagic mucilage community of the northern Adriatic Sea. Sci Total Environ 165:59-63

Fuks D (1995) Role of bacterioplankton in the northern Adriatic Sea ecosystem. PhD thesis, University of Zagreb. 'Ruđer Bošković' Institute, Rovinj (in Croatian)

Gilmartin M, Degobbis D, Revelante N. Smodlaka N (1990) The mechanism controlling plant nutrient concentrations in the northern Adriatic Sea. Int Rev Ges Hydrobiol 75: $425-445$
Herndl GJ (1988) Ecology of amorphous aggregations (marine snow) in the Northern Adriatic Sea. Il. Microbial density and activity in marine snow and its implication to overall pelagic processes. Mar Ecol Prog Ser 48:265-275

Herndl GJ (1992) Marine snow in the Northern Adriatic Sea: possible causes and consequences for a shallow ecosystem. Mar Microb Food Webs 6:149-172

Herndl GJ, Peduzzi P (1988) Ecology of amorphous aggregations (marine snow) in the Northern Adriatic Sea: I. General considerations. PSZN I: Mar Ecol 9:79-90

Kaltenböck E, Herndl Gl (1992) Ecology of amorphous aggregations (marine snow) in the Northern Adriatic Sea. IV. Dissolved nutrients and the autotrophic community associated with marine snow. Mar Ecol Prog Ser 87: $147-159$

Kattner G, Gercken G, Eberlein K (1983) Development of lipids during the spring plankton bloom in the northern North sea. I. Particulate fatty acids. Mar Chem 14:149-162

Kiørboe T, Andersen KP, Damm HG (1990) Coagulation efficiency and aggregate formation in marine phytoplankton. Mar Biol 107:235-245

Malej A (1995) Gelatinous aggregates in the northern Adriat.c Sea. Bull Inst Océanogr Monaco 15:149-15?

Malej A, Harris RP (1993) Inhibition of copepod grazing by diatom exudates: a factor in the development of mucus aggregates. Mar Ecol Prog Ser 96:33-42

Mayzaud P, Chanut JP, Ackman RG (1989) Seasonal changes of the biochemical composition of marine particulate matter with special reference to fatty acids and sterols. Mar Ecol Prog Ser 56:189-204

Mayzaud P, Claustre H, Augier P (1990) Effect of variable nutrient supply on fatty acid composition of phytoplankton grown in an enclosed experimental ecosystem. Mar Ecol Prog Ser 60:123-140

Monti M, Welker C, Dellavalle G, Casaretto L, Fonda-Umani $S$ (1995) Mucous aggregates under natural and laboratory conditions: a review. Sci Total Environ 165:145-154

Morris RJ, McCartney MJ, Joint IR, Robinson GA (1985) Further studies of a spring phytoplankton bloom in an enclosed experimental ecosystem. J Exp Mar Biol Ecol 86: $151-170$

Najdek M, Puskaric S, Bochdansky AB (1994) Contribution of zooplankton lipids to the flux of organic matter in the northern Adriatic Sea. Mar Ecol Prog Ser 111:241-249

Posedel N, Faganeli J (1991) Nature and sedimentation of suspended particulate matter during density stratification in shallow coastal waters (Gulf of Trieste, northern Adri. atic). Mar Ecol Prog Ser 77:135-145

Revelante N, Gilmartin M (1991) The phytoplankton composition and population enrichment in gelatinous macroaggregates' in the northern Adriatic during the summer of 1989. J Exp Mar Biol Ecol 146:217-233

Riebesell U (1991) Particle aggregation during a diatom bloom. II. Biological aspects. Mar Ecol Prog Ser 69:281-291

Smetacek VS (1985) Role of sinking in diatom life-history cycles: ecological, evolutionary and geological significance. Mar Biol 84:239-251

Smodlaka N (1986) Primary production of the organic matter as an indicator of the eutrophication in the northern Adriatic Sea. Sci Total Environ 56:211-220

Stachowitsch M, Fanuko N, Richter M (1990) Mucus aggregates in the Adriatic sea: an overview of types and occurrences. PSZN I: Mar Ecol 11:327-350

Volkman JK, Jeffrey SW, Nichols PD, Rogers CI, Garland CD (1989) Fatty acid and lipid composition of 10 species of microalgae used in mariculture. J Exp Mar Biol Ecol 128: $219-240$

Manuscript first received: August 28, 1995

Revised version accepted: April 9, 1996 